\title{
Personality traits and gender-specific income expectations in Dutch higher education
}

\author{
Ariana Need $\cdot$ Uulkje de Jong
}

Received: 22 January 2007/Accepted: 1 March 2007/Published online: 27 March 2007

(C) Springer Science+Business Media B.V. 2007

\begin{abstract}
In this article we examine gender differences in income expectations of students in higher education. We found quite large gender differences. Men and women differ significantly in the income they expect to earn at the top of their career. We examined how much personality traits contribute to explain gender differences in income expectations, and to what extent personality typologies can add to insights about earnings potential derived from human capital theory. The research shows that personality does affect expected income, that impact goes beyond personality's indirect effects, which are conveyed largely through gender differences and students' choice of study subject.
\end{abstract}

Keywords Income expectations $\cdot$ Gender differentials $\cdot$ Inequality $\cdot$ Higher education

\section{Introduction}

A study published by the Dutch periodical Elsevier in 2002 showed large differences between the incomes of male and female graduates in higher education, as well as between graduates from different fields of study (Elsevier 2002). The Guide to Higher Education also shows large income differentials between graduates in different disciplines (Steenkamp et al. 2001). Webbink (1999) found that graduates from the most difficult courses of study did not have the highest income. The highest earners were those who had studied medicine and law, while the incomes of physics graduates did not exceed the university average (see also Webbink and Hartog 2004). In addition, women's incomes were found to be lower than those of men (Webbink 1999; Webbink and Hartog 2004).

In this article we explore a few possible explanations for the income differentials between men and women. One of the most well known studies of income differences

\footnotetext{
A. Need $(\bowtie)$

Sociology, Radboud University, P.O. Box 9104, Nijmegen 6525 SG, Netherlands e-mail: ariana@ru.nl

U. de Jong

Educational Sciences, University of Amsterdam, Amsterdam 1090 GE, Netherlands
} 
between the sexes is that of Gary Becker (1964). Becker applies the notion of investment in human capital when looking at the choice of whether or not to continue education beyond high school. The main starting point of human capital theory is that education is an investment of time and money now in exchange for an income at some future time (Freeman 1986). Women expect to care for children at some point in the future. In consequence, they foresee being unavailable for the labor market during certain periods in their life. According to Becker, that is why women choose fields of study that prepare them for occupations with flatter income curves. They also choose jobs that require less effort (Becker 1985). Moreover, compared to men, women are assumed to attach less importance to having a career and intellectual challenge in their work. Instead they are seen to put more value on ease, flexible hours and a pleasant work environment (Filer 1985; Need et al. 2001). A final, and related explanation of gender differences in income is that men are better in negotiating with their employees than women (Groot and Oosterbeek 1994).

The above-mentioned differences between men and women in expectations for the future lead them to choose different fields of study. The differences in their preferred study areas could possibly be a cause of the income divergence later in their careers (Elsevier 2000; VSNU 2001). Statistics and research have confirmed gender differences in students' choice of field of study (Allen et al. 2003; CBS, various years; Dronkers 1982; Van Hout 1996). For instance, men are more often found in technical fields of study, while women are over-represented in disciplines related to language and culture (De Jong et al. 1998). In this article we do not use field of study only as a possible explanation for the income differences between men and women; we look at personality traits as well. The idea is to explore the extent to which personality can help explain the differences between men and women in both incomes and choice of study area.

The research reported on in this article is based on a large-scale national survey of firstyear students in higher education in the Netherlands in 1997. These students were given a questionnaire that asked, among other things, about their expected future income, their field of study and personality traits. We answer three questions about the expectations of students in higher education regarding their future income. In so doing, we make the assumption that students can realistically assess their future earnings. To confirm that this is a reasonable assumption, we first answer the question to what extent do the income expectations of students correspond to the incomes they actually do obtain. Our second question asks how large are the differences between men and women in their expected income. The third question that we answer with this research is to what extent can we explain these differences. For this we investigate the degree to which personality traits can contribute to explain the income differentials between men and women, and in this regard, the degree to which personality effects can be put forward as a supplement to human capital theory.

\section{Choice of Study and Personality}

This article explores the extent to which personality traits contribute to explain the income differentials between men and women, as well as the degree to which personality effects can be put forward to supplement human capital theory in explaining gender differences in income. Four groups of factors are assumed to influence (expected) income: social origin, talent, desires for the future and the choice of study area (compare Blau and Duncan 1967). The causal sequence assumed in the model is as follows: background characteristics $\rightarrow$ ability $\rightarrow$ desires for the future $\rightarrow$ choice of study $\rightarrow$ income (expectations). We 
predict that our addition of personality traits to this model will substantially enrich the explanation of man-woman differences in expected income. Personality is assumed not only to have an indirect effect on income through its influence on choice of study area, but also a direct effect on expected income.

In the Netherlands, Van Eijck and De Graaf (2001) showed a considerably large influence of personality on the level of education achieved, and this effect was largely independent of social origin. They also found the effect of personality traits to be stronger for men than for women. In this study, we explore the extent to which personality traits influence people's choice of field of study. We also look at the direct effects of personality traits on the expectations students have regarding their future income.

In psychology there is general consensus about the applicability and the validity of the five-factor model (FFM), also called the "Big 5" (Cattell 1943; Digman 1990; Eysenck 1947; Goldberg 1993; McCrae and John 1992). The five basic factors are extraversion, agreeableness, conscientiousness, emotional stability versus neuroticism, and openness to experience. Various studies have shown that these personality traits differ significantly among students in different fields of study (Smart and Elton 1975; De Fruyt and Mervielde 1996). These personality traits have also been shown to influence the level of education completed (Van Eijck and De Graaf 2001), educational achievement (De Fruyt and Mervielde 1996) and choice of occupation (Van den Berg and Feij 1993). Regarding the influence of personality on income, however, nothing is as yet known.

People convey personality traits not only through their gestures and expressions, but also through their interests and preferences. Some people, for example, gravitate towards technical activities, while others prefer active hobbies or pastimes that enable them to make a lot of social contacts. Holland $(1959,1997)$ developed a theory in which he distinguished six different personality preferences, the so-called "RIASEC-model". According to this model, the six, theoretically distinguishable types are realistic, investigative, artistic, social, enterprising and conventional. One of Holland's central hypotheses is that people select educational and professional environments that enable them to best realize their preferences. The RIASEC-model is often used as a basis for making vocational and career tests.

In this research we use both the FFM and the RIASEC typologies to explain manwoman differences in expectations of future income. While it turns out that there are some correlations between the different FFM and RIASEC characteristics, the correlations found are very small (Gottfredson et al. 1993). For example, "social" and "enterprising" career preferences are positively correlated with "extraversion"; "investigative" and "artistic" correlate with "openness"; and "conventional" career preferences correlate with "conscientiousness" (Gottfredson et al. 1993). Because an earlier study of educational achievement established the value of using the FFM as well as the RIASEC typology (De Fruyt and Mervielde 1996), we use both in this research.

\section{Data and Operationalization}

The research questions were answered by making use of the dataset "Participation in Higher Education' commissioned by the Dutch Ministry of Education, Culture and Science and collected by the SCO-Kohnstamm Institute and the Foundation for Economic Research (SEO). A survey was done of first-year students in higher education at colleges and universities in the Netherlands in 1997. The respondents were selected by stratified sample based on type of higher education (university or professional college), sector of 
study, academic discipline, and the university or professional college attended. The respondents received a written questionnaire in both their first and second year of study. This research used data from both questionnaires. Further, the data used were weighted according to the national distribution of level of school attended (university or professional college) and sector of study, and then corrected for survey drop-outs. We have complete information for 1,419 respondents: 470 university students en 949 professional college students.

The dependent variable in our analysis is the expected income. In their first year of study the respondents were asked what starting salary and what maximum salary (net in Dutch guilders per month) they expected to earn. ${ }^{1}$ We converted these guilders into euros. To answer our first research question we used the expected starting salary; to answer the second and third research questions, we analyzed the expected maximum salary.

We asked the students about personality traits in a very direct fashion. The respondents were given a list of personality traits and asked to rate each of the traits using a number between 0 (does not apply to me at all) and 10 (applies strongly to me). Thus the numbers reflected the degree to which the students felt that the personality traits listed characterized them. For the FFM typology, the personality traits were extraversion, agreeableness, conscientiousness, emotional stability and openness. For the RIASEC typology, these were realistic, investigative, artistic, social, enterprising and conventional. In addition to the personality traits, our analyses examined other explanatory variables. The sections below describe these and how they were operationalized.

\subsection{Background}

Background was included in the analysis by considering two characteristics of the parents: their income and their education. Income is the sum of the net monthly earnings of both parents. Parents' level of education was categorized into four groups: (1) primary and lower middle school, (2) higher middle school, (3) professional college and (4) university.

\subsection{Ability}

The analyses further controlled for ability. Two measures for ability were used: the students' average final exam score and their age. Respondents were asked to provide the results of their middle-school final exams. (In the Netherlands there are three levels of middle school: "VWO', which prepares young people for further education at the university level, "HAVO', which prepares young people for further education at a professional college, and "MAVO", which prepares young people for a trade. Students who first attend a MAVO-level middle school may upon completion of their MAVO diploma go on to attend a HAVO-level middle school. The same holds true for HAVO students who might later earn a diploma at the VWO level.) Students holding multiple diplomas were asked to provide the results of their highest-level diploma. An average final-exam score (minimum 1, maximum 10) was calculated only for respondents who provided results for a minimum of four subjects.

\footnotetext{
${ }_{1}$ Net income per month was chosen over gross monthly income because it is clearer what the amount is that is transferred to the employee's bank account. We assume that a net salary is more concrete and thus more easily imaginable than a gross salary. Similarly, monthly salary was chosen instead of yearly income. Naturally this takes no account of bonuses or whether individuals foresee earning income from sources other than salary.
} 


\subsection{Field of Study}

In their first year, the respondents were asked what was their field of study. The study areas were then categorized into the following sectors: economics, social studies, health, agriculture, physics, education (applies only for students at professional colleges, since universities do not offer this field of study), law (applies only to university students because professional colleges do not offer law studies), language and culture, and technology.

\subsection{Future Desires}

To test the human capital hypothesis that women expect lower incomes than men because having a career is of less importance to them and they instead place more value on having children, two variables were adopted to measure future desires. Respondents were asked to value certain desires related to their future position in society. For a number of aspects, such as "children" and "career", they rated the importance they attributed to achieving that objective in the future. They did this by assigning a value between 0 (no, not at all important to me) and 10 (yes, very important to me).

The variable "children" reflects the scores provided by the respondents for the aspect "children". Similarly, the variable "career" indicates the importance that the respondents attached to their career. Career is a range that runs from 0 to 10 and is constructed based on three items: work with career possibilities, high salary and fringe benefits (alpha $=0.68$ ).

\subsection{Do the Students Have Realistic Expectations?}

In this article we used the students' expectations of their future income as an indirect means of measuring what their actual future income will be. In so doing, we assume that people can make a reasonable estimations of their future income. Economists make the same assumption when they use actual income as a measure of future income. While much is written in economic theory about expected income, most empirical economic studies base their conclusions on actual income rather than on income expectations (Berger 1988; Willis and Rosen 1979). ${ }^{2}$ The question arises then of whether we are justified in making the assumption that people are indeed able to realistically estimate what their future income will be. The first question answered in this article is therefore to what extent do the estimates students make of their future income correspond to the incomes they actually attain.

Only a few studies have attempted to answer this question. Sometimes incomes earned by earlier cohorts of students are used as a proxy for realized income (Berndt and Miller 1990; Betts 1996). It is better, however, to compare expectations of future income with individual incomes attained, rather than with aggregated data. This was done for the Netherlands (Webbink 1999; Webbink and Hartog 2004). They measured the earnings expectations of students in 1991 and compared these with their actual starting salaries in 1995. Their results show that students can make reasonable estimations of their future income, though for the most part they overestimate their income by about $10 \%$. Webbink and Hartog found no systematic differences between men and women in income expectations compared with the actual salary attained. It turns out that men and women do not

\footnotetext{
${ }^{2}$ Recently, a number of empirical studies have appeared that do address income expectations (Betts 1996; Blau and Ferber 1991; Webbink 1999; Webbink and Hartog 2004).
} 
Table 1 Comparison of expected net starting salaries — in euros per month — with the actual salaries earned by the cohort entering the labor market in 2000 , by field of study

\begin{tabular}{lllcc}
\hline & Salary earned & Salary expected & $\begin{array}{c}\text { Difference } \\
\text { earned - expected }\end{array}$ & $\begin{array}{l}\text { \% Difference } \\
\text { earned - expected }\end{array}$ \\
\hline Field of study & $* * *$ & $* * *$ & n.s. & n.s. \\
Economics & 1,202 & 1,279 & -77 & -6.0 \\
Social studies & 1,083 & 1,214 & -131 & -10.8 \\
Health & 1,221 & 1,240 & -19 & -1.5 \\
Agriculture & 1,138 & 1,197 & -59 & -4.9 \\
Physics & 1,129 & 1,342 & -213 & -15.9 \\
Education & 1,065 & 1,160 & -95 & -8.2 \\
Law & 1,278 & 1,405 & -127 & -9.0 \\
Language/culture & 1,055 & 1,142 & -86 & -7.6 \\
Technology & 1,332 & 1,489 & -157 & -10.5 \\
Average & 1,179 & 1,282 & -103 & -8.1 \\
\hline
\end{tabular}

$* * * p<0.001, * * p<0.01, * p<0.05$

Source: "Participation in Higher Education"' cohort 1997 and Elsevier (2000); authors' calculations

differ with respect to the accuracy of their estimates (Webbink 1999; Webbink and Hartog 2004).

Unlike Webbink (1999) and Webbink and Hartog (2004) we have no data on the actual salaries the students realize. The students in our sample (all of whom started their studies in 1997) will enter the labor market in 2001 at the earliest. That is why we compare their expected starting salaries with the aggregated incomes attained by the cohort of students who entered the labor market in 2000. This data was taken from the jobs special of the Dutch periodical Elsevier (2000). We translated the names of the study areas the students in the survey provided to the fields reported by the data in Elsevier. We then compared the income expectations of the students with the average incomes reported in Elsevier. Table 1 shows the degree to which the students' expectations of future earnings correspond to the starting salaries that the cohort entering the labor market in 2000 actually earned.

Comparing the salaries that first-year students expect with the aggregated data of salaries earned by the labor-market cohort that entered the job market 3 years later, Table 1 shows that students overestimate their starting salary by an average $8.1 \%$. We found no significant differences across the various fields of study in the accuracy of estimates made by the students. This finding is in line with that of previous research (Webbink 1999; Webbink and Hartog 2004).

In this research, we explore the gender-specific income expectations of students in higher education. Because Elsevier (2000) did not report the incomes of students from different study fields apart for men and women, we are unable with the available data to answer the question of whether there is a difference between men and women in their ability to estimate their future earnings accurately. However, this question has been answered before (Webbink 1999; Webbink and Hartog 2004). ${ }^{3}$ According to this research, students can estimate their future income fairly accurately, although they overestimate

\footnotetext{
3 The questionnaire that was used for this research was based largely on that used by Webbink (1999). However, Webbink's questionnaire lacked questions regarding personality traits, which meant that Webbink's data could not be analyzed as part of this research.
} 
their future earnings by about $10 \%$. Moreover, they found no systematic differences between men and women in the discrepancy between the income they expect to earn and their actual future earnings; men and women can thus estimate their future income equally well (Webbink 1999; Webbink and Hartog 2004). Based on these results, we think it is justified in this analysis of income expectations to assume that the relationships found apply not only for the expected income, but also for the actual future income.

\section{Descriptive Analysis}

The second question that we answer in this article is the descriptive one of how men and women differ in their estimates of future income. Table 2 provides an answer to this question. In this table we show the students expected starting salary (net monthly) and the maximum salary (net monthly) they expect to earn at the top of their career.

On average, the first-year students expect to earn a starting salary of 1,282 euros per month. Men on average estimate their starting salary will be some 1,389 euros, considerably higher than women, who expect to earn 1,179 euros per month on average after completing their studies. This difference between men and women is significant. The

Table 2 Income expectations of first-year students in higher education, 1997, by sex, parents' education, level of school attended and field of study (number of occurrences in parentheses)

\begin{tabular}{lll}
\hline & $\begin{array}{l}\text { Net starting salary } \\
\text { (euros per month) }\end{array}$ & $\begin{array}{l}\text { Net salary at the top of career } \\
\text { (euros per month) }\end{array}$ \\
\hline Sex & $* * *$ & $* * *$ \\
Women & $1,179(724)$ & $1,964(724)$ \\
Men & $1,389(695)$ & $2,564(695)$ \\
Parents' education & $* * *$ & $* *$ \\
Primary + lower middle school & $1,248(423)$ & $2,157(423)$ \\
Higher middle school & $1,208(370)$ & $2,247(370)$ \\
Professional college & $1,333(390)$ & $2,331(390)$ \\
University & $1,373(236)$ & $2,337(236)$ \\
Level of school attended & $* * *$ & $* * *$ \\
Professional college & $1,204(949)$ & $2,034(949)$ \\
University & $1,439(470)$ & $2,710(470)$ \\
Sector of sector & $* * *$ & $* * *$ \\
Economics & $1,279(352)$ & $2,341(352)$ \\
Social studies & $1,214(209)$ & $2,062(209)$ \\
Health & $1,239(149)$ & $2,081(149)$ \\
Agriculture & $1,197(61)$ & $2,239(61)$ \\
Physics & $1,342(68)$ & $2,293(68)$ \\
Education & $1,160(139)$ & $1,185(139)$ \\
Law & $1,405(65)$ & $2,759(65)$ \\
Language and culture & $1,142(135)$ & $1,980(135)$ \\
Technology & $1,489(243)$ & $2,644(243)$ \\
Average & $1,282(1,419)$ & $2,258(1,419)$ \\
\hline
\end{tabular}

$* * * p<0.001, * * p<0.01, * p<0.05$

Source: "Participation in Higher Education", cohort 1997; authors' calculations 
difference between the expected incomes of men and women is even larger when we look at the salaries the students expect to be earning at the top of their careers: on average men expect to be earning 2,564 euros (net per month) at the top of their career, while women expect to be earning 600 euros per month less (1,964 euros). Thus, there is a significant difference between men and women in the net monthly salary they expect to be earning at the top of their professional careers.

Table 2 also presents a breakdown of students' expected salary according to the educational level of the parents, the student's own level of school attended, and the sector of study. Children of higher educated parents expect to earn a higher salary (both starting salary and maximum salary) compared with children whose parents have a lower educational level. University students expect to earn significantly more than their counterparts at professional colleges. This difference is larger for the maximum salary than for the starting salary. Finally, we see considerable differences in expected earnings among students from different fields of study. Students in the sectors "language and culture" and "education", (professional college level only) expect to earn the least upon completing their studies; students of law (university level only) and technology estimate their future earnings highest.

The third research question seeks to explain the difference in expected incomes between men and women. This explanation is sought on the one hand in the human capital theory and on the other hand in man-woman differences in personality. Ability is controlled for in the analysis. To test the hypothesis that income differences can be attributed to women's attaching less importance to having a career and putting more value instead on a pleasant work environment and having children (Filer 1985), we compare men and women's desires for the future. Regarding the future desires of men and women we can conclude that women and men do not differ in the importance they attach to having children in the future: the average score of men and of women was 6.9 on a scale from 0 (having children is not important) to 10 (having children is very important). Men and women do differ significantly in the importance they attach to having a career. On a scale from 0 to 10 men and women differ by almost a half point (men score 7.3 compared to 6.9 for women).

In the multivariate analysis presented in section 6 , we answer the question of whether and to what degree these differences between men and women in their desires for the future can explain the differences in the income they expect. First we present in Table 3 the differences between men and women in a number of personality traits. The hypothesis that we want to test in this study is that the differences between men and women in income expectations are attributable to their choice of a certain field of study, which is influenced in turn by personality traits.

Table 3 shows that men and women differ significantly in most personality traits. We find for the FFM no significant differences with regard to agreeableness. Men are less extrovert, less conscientious and less open than women, and more emotionally stable, whereby the difference in the degree of neuroticism is particularly striking. On a scale from 0 to 10 , men score on average a whole point lower than women, which is to say that women are less emotionally stable than men. Using the RIASEC typology, there are no significant differences between men and women the degree to which they are artistic or realistic. Men did typify themselves as intellectual and conventional significantly more often than women. In contrast, women typified themselves as social and enterprising more often than men.

Table 4 presents the personality traits of first-year students according to their field of study. This table shows that most of the personality traits differ significantly across the different study areas. The FFM shows significant differences across fields of study, particularly for conscientiousness, emotional stability and openness. The findings presented in 
Table 3 Personality traits (FFM and RIASEC) of first-year students in higher education, 1997, by sex $(N=1,210)$

\begin{tabular}{llll}
\hline & Women & Men & Level of significance \\
\hline FFM & 5.4 & & \\
Extraversion & 5.1 & 4.9 & 0.00 \\
Agreeableness & 7.1 & 5.1 & 0.80 \\
Conscientiousness & 4.5 & 6.9 & 0.00 \\
Neuroticism & 7.0 & 3.5 & 0.00 \\
Openness & & 6.3 & 0.00 \\
RIASEC & 7.7 & & \\
Realistic & 6.9 & 7.8 & 0.17 \\
Investigative & 5.2 & 5.0 & 0.00 \\
Artistic & 7.9 & 7.3 & 0.25 \\
Social & 7.3 & 6.9 & 0.00 \\
Enterprising & 5.1 & 5.4 & 0.00 \\
Conventional & & & 0.01 \\
\hline
\end{tabular}

Source: "Participation in Higher Education"' cohort 1997; authors' calculations

Table 4 corroborate earlier research to a great degree. De Fruyt and Mervielde (1996) also found emotional instability to be more common among students of social studies and less common among, for example, students of law. Moreover, the study done by De Fruyt and Mervielde (1996) also found students of language and culture to be the least conscientious. With regard to openness, they also found students in the education sector to be the most open.

Moreover, regarding the RIASEC scale our findings agree with those of De Fruyt and Mervielde (1996). They also found that students in the more technical study areas are the most realistic. Students of language and culture are the least realistic, but on the other hand, they are the most artistic. Economics students turn out to be the least investigative-but the most enterprising; physical sciences students are the most investigative. It also turns out that students in the education sector are the most social. In the next section a multivariate analysis is performed which will investigate the direct influence of personality on expected earnings. It will also examine the degree to which differences in personality can explain the man-woman differences in expected income.

\section{Multivariate Analysis}

The third question addressed in this research is to what extent can we explain the differences in expected earnings between men and women. For this we look at the relative influence of different factors. We use multivariate analysis to examine the relative influence of choice of study area, personality traits, and differences in ambitions and desires for the future. In the analysis, we control for ability and for background, the latter by using characteristics of the parents such as their income and education. An OLS regression might be prone to heteroscedasticity (Webbink and Hartog 2004); therefore we perform our analysis on the log of the expected income. ${ }^{4}$

\footnotetext{
${ }^{4}$ We checked to what extent we suffered from multicollinearity. However, the values for the tolerance and the VIF indicated that this was not the case.
} 


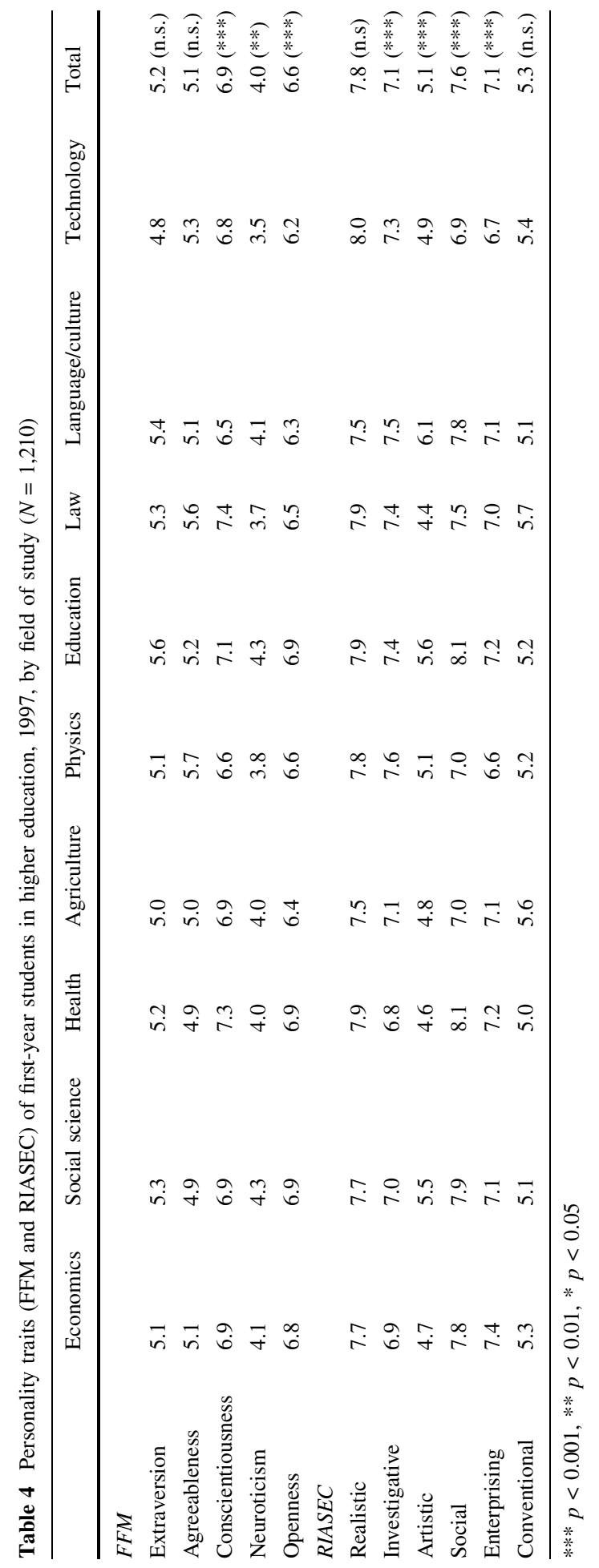


The results of the analysis are found in Table 5. We do the analysis separately for university and professional college students. Table 5 presents for six different models the non-standardized regression coefficient of sex in a regression analysis with the log of the expected maximum salary as the dependent variable. This non-standardized regression coefficient can be interpreted as the difference between men and women in expected maximum salary, controlling for various factors.

The first model in Table 5 shows the difference between men and women in expected maximum salary, without our taking into account the influence of other factors. The regression coefficient for women attending professional college is -0.306 . This difference is smaller at universities, where the regression coefficient for women is -0.169 . In the next models we add, step by step, a group of explicative factors. Groups of factors that provide a good explanation of the man-woman differences in expected earnings will lower the resulting difference between men and women in their expected income.

In the second model we add characteristics of the parents, since we want to control for these in the analysis. It turns out that the difference between men and women in their expected maximum salary increases for professional college students when we take into account the income and educational level of the parents, and whether or not the mother works outside the home. We compare the subsequent model with model 2.

In model 3 we control not only for characteristics of the parents, but also for ability. We see that ability cannot account for the difference between men and women, since the regression coefficient in models 2 and 3 do not differ.

In model 4 we add to model 3 desires for the future "children" and "career". At professional colleges, differences in future desires does not significantly decrease the difference between men and women in expected income; but at the universities the regression coefficient drops from -0.163 to -0.138 , which is significant. Thus, at the university, differences in men and women in their desire for a "career" or "children" is a good explanation for the differences in expected incomes. However, there are still differences between men and women that are not accounted for.

In model 5 we see that field of study forms an important determinant of the differential between men and women in their expected top income. For professional college students, field of study drops the man-woman difference residual in model 4 to -0.256 ; at the universities it can account for another significant drop in the man-women regressioncoefficient.

In model 6 we see the additional influence of personality traits on man-woman differences in expected maximum salary. Compared to model 5, in which we controlled for

Table 5 Analysis of the natural $\log$ of the expected maximum salary: women compared to men, $(N=1,210)$

\begin{tabular}{|c|c|c|c|c|c|}
\hline & & $\begin{array}{l}\text { Professional } \\
\text { college }\end{array}$ & $\begin{array}{l}\text { Level of } \\
\text { significance }\end{array}$ & University & $\begin{array}{l}\text { Level of } \\
\text { significance }\end{array}$ \\
\hline 1 & Differences between men and women & -0.306 & 0.02 & -0.169 & 0.03 \\
\hline 2 & $\begin{array}{l}\text { Model } 1+\text { background factors controlled } \\
\text { for }\end{array}$ & -0.316 & 0.02 & -0.168 & 0.03 \\
\hline 3 & Model $2+$ ability controlled for & -0.316 & 0.02 & -0.163 & 0.03 \\
\hline 4 & Model 3 + future desires controlled for & -0.310 & 0.02 & -0.138 & 0.03 \\
\hline 5 & Model $4+$ field of study controlled for & -0.256 & 0.03 & -0.121 & 0.03 \\
\hline 6 & Model $5+$ personality traits controlled for & -0.229 & 0.03 & -0.108 & 0.03 \\
\hline
\end{tabular}

Source: "Participation in Higher Education"' cohort 1997; authors' calculations 
Table 6 Analysis of the natural log of the expected maximum income in euros per month, parameter estimates for model 6 , professional college and university analyzed separately $(N=412$ for university and 798 for professional college)

\begin{tabular}{|c|c|c|c|c|c|c|}
\hline & \multicolumn{3}{|c|}{ Professional college } & \multicolumn{3}{|c|}{ University } \\
\hline & $\mathrm{b}$ & SE & Sig. & b & SE & Sig. \\
\hline (Constant) & 7.291 & 0.202 & 0.000 & 7.277 & 0.235 & 0.000 \\
\hline \multicolumn{7}{|l|}{ Sex } \\
\hline Man (reference) & - & - & - & - & - & - \\
\hline Woman & -0.229 & 0.027 & 0.000 & -0.108 & 0.031 & 0.001 \\
\hline \multicolumn{7}{|l|}{ Parents' characteristics } \\
\hline \multicolumn{7}{|l|}{ Educational level parents } \\
\hline Primary school + lower middle school & 0.282 & 0.042 & 0.000 & 0.012 & 0.041 & 0.775 \\
\hline Higher middle school & 0.340 & 0.042 & 0.000 & 0.009 & 0.042 & 0.891 \\
\hline Professional college & 0.289 & 0.042 & 0.000 & 0.067 & 0.035 & 0.056 \\
\hline University (reference) & - & - & - & - & - & - \\
\hline Income parents (net per month) & 0.000 & 0.000 & 0.000 & 0.000 & 0.000 & 0.000 \\
\hline \multicolumn{7}{|l|}{ Ability } \\
\hline Average final exam score & 0.028 & 0.021 & 0.177 & 0.040 & 0.021 & 0.058 \\
\hline Age & 0.006 & 0.003 & 0.046 & 0.003 & 0.005 & 0.533 \\
\hline \multicolumn{7}{|l|}{ Desires and expected opportunities } \\
\hline Children & 0.005 & 0.004 & 0.229 & 0.001 & 0.006 & 0.886 \\
\hline Career & 0.009 & 0.006 & 0.146 & 0.032 & 0.008 & 0.000 \\
\hline \multicolumn{7}{|l|}{ Sector of study } \\
\hline Economics (reference) & - & - & - & - & - & - \\
\hline Social studies & -0.043 & 0.038 & 0.260 & -0.153 & 0.049 & 0.002 \\
\hline Health & -0.202 & 0.042 & 0.000 & 0.077 & 0.055 & 0.160 \\
\hline Agriculture & -0.063 & 0.058 & 0.277 & -0.145 & 0.076 & 0.055 \\
\hline Physics & -0.121 & 0.073 & 0.099 & -0.205 & 0.057 & 0.000 \\
\hline Education & -0.064 & 0.037 & 0.084 & & n.a. & \\
\hline Law & n.a. & & -0.070 & 0.051 & 0.168 & \\
\hline Language and culture & -0.041 & 0.046 & 0.365 & -0.274 & 0.055 & 0.000 \\
\hline Technology & 0.045 & 0.037 & 0.229 & -0.050 & 0.048 & 0.295 \\
\hline \multicolumn{7}{|l|}{ Personality traits (FFM) } \\
\hline Extraversion & -0.000 & 0.005 & 0.993 & 0.009 & 0.006 & 0.137 \\
\hline Agreeableness & -0.002 & 0.005 & 0.705 & 0.000 & 0.006 & 0.937 \\
\hline Conscientiousness & 0.003 & 0.006 & 0.644 & 0.009 & 0.007 & 0.205 \\
\hline Neuroticism & -0.015 & 0.005 & 0.002 & -0.012 & 0.006 & 0.050 \\
\hline Openness & -0.004 & 0.006 & 0.543 & 0.001 & 0.008 & 0.908 \\
\hline \multicolumn{7}{|l|}{ Personality traits (RIASEC) } \\
\hline Realistic & 0.007 & 0.008 & 0.387 & -0.012 & 0.012 & 0.320 \\
\hline Investigative & 0.009 & 0.007 & 0.212 & 0.024 & 0.011 & 0.022 \\
\hline Artistic & 0.008 & 0.005 & 0.104 & -0.011 & 0.006 & 0.057 \\
\hline Social & -0.019 & 0.009 & 0.031 & -0.006 & 0.011 & 0.573 \\
\hline
\end{tabular}


Table 6 continued

\begin{tabular}{|c|c|c|c|c|c|c|}
\hline & \multicolumn{3}{|c|}{ Professional college } & \multicolumn{3}{|c|}{ University } \\
\hline & $\mathrm{b}$ & SE & Sig. & $\mathrm{b}$ & SE & Sig. \\
\hline Enterprising & -0.004 & 0.008 & 0.640 & 0.008 & 0.010 & 0.441 \\
\hline Conventional & -0.002 & 0.005 & 0.733 & 0.004 & 0.007 & 0.517 \\
\hline$R^{2}$ & 0.246 & & & 0.276 & & \\
\hline
\end{tabular}

Source: "Participation in Higher Education" cohort 1997; authors' calculations

parents' characteristics, ability, desires for the future, and field of study, for professional college students personality traits further lowers the difference between men and women in their expected income to -0.229 ; at the university level the effect of personality on manwoman differences is somewhat smaller but still significant.

The difference between men and women in their expected maximum income remains significant, even in the last model. Still, with the factors included in our final model we have accounted for $25 \%$ of the man-woman difference in expected maximum salary for students at professional colleges $(100 \% *((0.306-0.229) / 0.306))$ and for $36 \%$ of the man-woman differences for university students $(100 \% *(0.169-0.108) / 0.169))$. In Table 6, on the following page, we present the direct effects of all factors in the last model.

Table 6 shows that in the last model there is still a significant direct effect of gender on the expected maximum income. At professional colleges, students whose parents have a university level education estimate their future income lowest. While at professional colleges the parents' educational level has a significant direct effect on the maximum salary expectations of students, this is not the case for university students.

Ability has no direct effect on the expected maximum salary. Neither is the effect of average final exam score or age significant. Further, age has a small significant direct effect on the expected maximum salary for students at professional students. Older students, on average, expected slightly higher incomes than do younger students. For university students, the effect of age is not significant.

We did find that field of study has a strong direct impact on students' income expectations. At the professional college level, expected earnings are the highest among economics students. Yet students in the technology sector do not estimate their future maximum salary significantly lower than students of economics. Students in the health sector at professional colleges estimate their maximum earnings lowest. Yet at the universities, it is the health-sector students who expect to earn the most; they do not differ significantly from economics students. At the universities, students of language and culture estimate their maximum salary the lowest.

While the effect of personality is in large part conveyed via the choice of study area (Holland 1959, 1997), ${ }^{5}$ we nonetheless find a few direct effects of certain FFM and RIASEC characteristics on expected income. From the FFM, we find that emotionally instable people predict they will earn less than their more emotionally stable counterparts. Recall from Table 3 that on a scale from 0 to 10 women score on average one point less than men in emotional stability. At the professional college level, the sociability factor has an additional significant direct effect. People who characterize themselves as more social

\footnotetext{
5 The effects of choice of study area are smaller in a model that includes personality traits, than in models without personality traits.
} 
expect to earn less than their less sociable counterparts. In Table 3, we saw that on a scale from 0 to 10 , women characterize themselves on average 0.5 points more sociable than men. At the university, people who characterize themselves as intellectual types expect to earn more. According to Table 3 , men score an average 0.5 points higher than women in this regard.

Finally, Table 6 shows that the importance that students at professional colleges attach to having children or a career does not lead them to estimate their maximum income higher or lower. At the university, the importance that students attach to their career does have a direct effect on expected income. Men consider their career an average 0.5 points more important than women.

\section{Conclusion}

In this article, we considered three questions regarding the income expectations of students in higher education. The first question addressed was to what degree do the expectations of students regarding their future income correspond to the salaries they actually earn. It turns out that students overestimate their future earnings by $8.1 \%$. Also, there are no significant differences between students from different fields of study in the accuracy with which they estimate their future earnings. These results agree with those of Webbink (1999) and Webbink and Hartog (2004), who found no systematic differences among students in the discrepancy between the income they expect and the salaries they actually obtain. We conclude therefore that measuring expected future income is a good way to estimate actual future earnings.

With the second question we wanted to find out how large the difference in income expectations is between men and women. It turns out that there are sizeable differences in expected incomes: men estimate their starting salary at 1,389 euros, women at 1,179 euros. There are also significant differences in the maximum salary expected: men predict that at the top of their career they will be earning an average 2,564 euros per month, while women estimate their maximum salary quite a bit lower, at 1,964 euros per month.

The last question that is answered in this research is to what extent can we explain these income differences between men and women. We looked at the relative influence of choice of study area, of personality and of differences in ambitions. With the factors in our model, for professional college students we explained $25 \%$ of the man-woman differences in expected maximum earnings; for university students we explained $36 \%$ of the differences. From the FFM, it turns out that the character trait "emotional stability" has a significant direct effect on the expected maximum salary for both the professional college and university students. At the professional college level, this personality trait has a significant effect; at the universities the personality trait "intellectual" also explains a degree of the difference in expected maximum salary.

In this research personality traits were asked for in a very direct manner, using only one indicator. To measure personality traits, Van Eijck and De Graaf (2001) use an instrument that is derived from a Dutch version of a standardized, truncated scale for the FFM (Gerris et al. 1998). They measure each personality trait by using six questions. De Fruijt and Mervielde (1996) use three scales ${ }^{6}$ of 12 items to measure each of six personality characteristics. Measuring personality traits using only a single indicator undoubtedly results in measurement errors. Nonetheless, we think that these errors have no ramifications for the

$\overline{6}$ These scales relate to activities, competencies and occupations. 
relationships found between personality traits and income expectations. This view is strengthened by the fact that the relationships found in our study between personality traits, gender and area of study corroborate the findings of a Flemish study that used a more precise measurement of personality traits (De Fruijt and Mervielde 1996). Moreover, measurements using only one indicator will vary less than when more indicators are used, and significant effects are less likely to be found. We therefore think that the significant effects that we found with our rough measurement of personality traits, will also be found with a more precise measurement of personality traits. Further research is needed to explore the degree to which our assumptions about the measurement of personality traits hold true.

The results described in this article support the hypothesis that personality traits do have a substantial influence on the income expectations of students in Dutch higher education. These effects are in large part independent of social origin (Van Eijck and De Graaf 2001), but correlate significantly with the choice of a specific area of study. In addition, we found significant differences in personality traits between men and women. Thus, personality traits have not only an indirect effect, conveyed via gender and the choice of a specific area of study, but also a direct effect that is independent of gender and chosen study area. This research has therefore shown the usefulness of supplementing the human capital theory with a study of personality traits when studying income expectations.

A final conclusion of this research is that some personality traits are more useful than others when it comes to realizing a high income. Emotional stability is one of the most important personality traits that influences the man-woman difference in income. Men and women generally differ a great deal in their degree of emotional stability (Feingold 1994). Although openness is similar to intelligence and is related to intellectual curiosity (Van Eijck and De Graaf 2001), it appears that intelligence is more important than openness when it comes to income. As in the research of De Fruijt and Mervielde (1996) we also conclude that the FFM, which is in standard use in psychological research can be usefully supplemented with Holland's RIASEC-typology (Holland 1959, 1997).

\section{References}

Allen, J., De Jong, U., Roeleveld, J., Verbeek, F., \& De Vries R. (2003). WO-monitor 2000-2001: Arbeidsmarktsucces van academici: Verschillen en determinanten. Utrecht: VSNU.

Becker, G. S. (1964). Human capital: A theoretical and empirical analysis with special reference to education. New York: National Bureau of Economic Research.

Becker, G. S. (1985). Human capital, effort, and the sexual division of labor. Journal of Labor Economics, 3(1), S33-S58.

van den Berg, P. T., \& Feij, J. A. (1993). Personality traits and job characteristics as predictors of job experiences. European Journal of Personality, 7(5), 337-357.

Berger, M. C. (1988). Predicted future earnings and choice of college major. Industrial and Labor Relations Review, 41(3), 418-429.

Berndt, T. J., \& Miller, K. E. (1990). Expectancies, values, and achievement in junior high school. Journal of Educational Psychology, 82(2), 319-326.

Betts, J. R. (1996). What do students know about wages?: evidence from a survey of undergraduates. Journal of Human Resources, 31(1), 27-56.

Blau, P. M., \& Duncan, O. D. (1967). The American occupational structure. New York, London: Wiley.

Blau, F. D., \& Ferber, M. A. (1991). Career plans and expectations of young women and men: The earnings gap and labor force participation. Journal of Human Resources, 26(4), 581-607.

Cattell, R. B. (1943). The description of personality: basic traits resolved into clusters. Journal of Abnormal and Social Psychology, 38(4), 476-506.

CBS (various years). http://statline.cbs.nl/StatWeb (visited February 19, 2007).

Digman, J. M. (1990). Personality structure: Emergence of the five-factor model. Annual Review of Psychology, 41, 417-440. 
Dronkers, J. (1982). Student-culture, social relations between students and grades. In E. A. Trotsenberg (Ed.), Higher education, a field of study (pp. 141-156). Frankfurt am Main: Peter Lang.

van Eijck, K., \& De Graaf, P. M. (2001). De invloed van persoonlijkheidskenmerken op het bereikte opleidingsniveau. Mens en Maatschappij, 76(4), 285-302.

Elsevier (2000). Banen special: arbeidsmarkt 2000 voor pas afgestudeerden. Amsterdam: Elsevier.

Elsevier (2002). Carrière. De beste banen. Amsterdam: Elsevier.

Eysenck, H. J. (1947). Dimensions of personality. London: Kegan Paul, Trench, Trubner \& Co.

Feingold, A. (1994). Gender differences in personality: A meta-analysis. Psychological Bulletin, 116(3), 429-456.

Filer, R. K. (1985). Male-female wage differences: The importance of compensating differentials. Industrial and Labor Relations Review, 38(3), 426-437.

Freeman, R. B. (1986). Demand for education. In O. Ashenfelter \& R. Layard (Eds.), Handbook of labor economics (Vol. 1) (pp. 357-386). Amsterdam: Elsevier Science Publishers.

de Fruyt, F., \& Mervielde, I. (1996). Personality and interests as predictors of educational streaming and achievement. European Journal of Personality, 10(5), 405-425.

Gerris, J. R. M., et al. (1998). Parents, adolescents and young adults in Dutch families: A longitudinal study. Nijmegen: Institute of Family Studies, University of Nijmegen.

Goldberg, L. R. (1993). The structure of phenotypic personality traits. American Psychologist, 48(1), 26-34.

Gottfredson, G. D., Jones, E. M., \& Holland, J. L. (1993). Personality and vocational interests: The relation of holland's six interest dimensions to five robust dimensions of personality. Journal of Counseling Psychology, 40(4), 518-524.

Groot, W., \& Oosterbeek, H. (1994). Stochastic reservation and offer wages. Labour Economics, 1(3/4), 383-390.

Holland, J. L. (1959). A theory of vocational choice. Journal of Counseling Psychology, 6(1), 35-45.

Holland, J. L. (1997). Making vocational choices: A theory of vocational personalities and work environments (3rd edn.). Odessa: Psychological Assessment Resources.

van Hout, J. F. M. J. (1996). Verschillen tussen wetenschapsgebieden (oratie). Den Haag: Vuga.

de Jong, U., et al. (1998). Deelname aan hoger onderwijs: Studiekeuze en motieven van eerstejaars 1995/96. Amsterdam: SCO-Kohnstamm Instituut/SEO.

McCrae, R. R., \& John, O. P. (1992). An introduction to the five-factor model and its applications. Journal of Personality, 60(2), 175-215.

Need, A., Visser, J., \& Fischer, A. (2001). Kansloze ambities?: Sekseverschillen in verwachtingen, ambities en loopbaan-inspanningen van promovendi aan de universiteit van Amsterdam. Tijdschrift voor Arbeidsvraagstukken, 17(4), 350-364.

Smart, J. C., \& Elton, C. F. (1975). Goal orientation of academic departments: A test of Biglan's model. Journal of Applied Psychology, 60(5), 580-588.

Steenkamp, F., Maljaars, W., \& Blankesteijn, E. (2001). Keuzegids Hoger Onderwijs 2001-2002. Amsterdam: Balans.

VSNU (2001). WO-monitor 2000: De arbeidsmarktpositie van afgestudeerden van de Nederlandse Universiteiten. Utrecht: Vereniging van Universiteiten (VSNU).

Webbink, D. (1999). Student decisions and consequences (dissertation). Amsterdam: SEO.

Webbink, D., \& Hartog, J. (2004). Can students predict starting salaries? Yes! Economics of Education Review 23(2), 103-113.

Willis, R. J., \& Rosen, S. (1979). Education and self-selection. Journal of Political Economy, 87(5), S7-S36. 